\title{
FACTORES QUE AFECTAN EL RECUENTO DE UFC EN LA LECHE EN TANQUE EN HATOS LECHEROS DEL NORTE DE ANTIOQUIA-COLOMBIA
}

\section{FACTORS THAT AFFECT COLONY FORMING UNITS IN BULK MILK OF NORTH ANTIOQUIA-COLOMBIA DAIRY FARMS}

\author{
Tatiana Ruiz-Cortés ${ }^{1}$, Stivenson Orozcoㄹ, Luz Stefany Rodríguez², Julián Idárraga³ ${ }^{3}$ Martha Olivera ${ }^{4}$
}

\begin{abstract}
1 MV, M.Sc, Ph.D, PD. Grupo de Investigación Biogénesis, Facultad de Ciencias Agrarias, Universidad de Antioquia, MedellínColombia; biogenesis1995@gmail.com; 2 Estudiantes Medicina Veterinaria, Facultad de Ciencias Agrarias, Universidad de Antioquia, ${ }^{3}$ Estudiante Zootecnia, Facultad de Ciencias Agrarias, Universidad de Antioquia. ${ }^{4}$ MV, Dr. Agr.Sc.
\end{abstract}

Rev. U.D.C.A Act. \& Div. Cient. 15(1): 147 - 155, 2012

\section{RESUMEN}

En el Departamento de Antioquia, Colombia, la producción primaria de leche bovina se desarrolla, en su mayoría, en la región del altiplano norte, con manejos de ordeño de tipos manual y mecánico. La calidad del producto define la comercialización del mismo, ya sea para consumo directo, luego de pasteurización o para su proceso y posterior producción de productos derivados. En ambos casos, la contaminación microbiana inicial, se constituye en factor definitivo para el destino de la leche producida. Una normativa específica por zonas para Colombia define los valores de unidades formadoras de colonias (UFC) permitidas, para que los productores puedan no sólo vender su producción sino, también, obtener bonificaciones importantes, al momento de la venta. El objetivo de este trabajo fue estudiar algunos factores que pueden afectar los conteos de UFC en tanque final de hatos lecheros del norte de Antioquia. Se midieron, se describieron con análisis univariado y se asociaron con regresión logística la variable dependiente: UFC en tanque y las variables independientes: tipo de ordeño, altitud en metros, tiempo de la leche en las cantinas (en minutos), distancia al tanque (en metros) y el número de vacas en ordeño. Se encontró que un punto crítico dentro de la rutina de ordeño fue el tiempo transcurrido desde el ordeño hasta llegada al tanque, sin alcanzar la cadena de frío. Otro factor crítico fue el número de vacas, quizás porque esto estaría aumentando el tiempo que dura el ordeño. Igualmente, la altitud, por su posible relación con la temperatura y la proliferación de bacterias.

Palabras clave: Unidades formadoras de colonia (UFC), ordeño manual, ordeño mecánico, geoposicionamiento (GPS).

\section{SUMMARY}

In Antioquia-Colombia, the primary milk production is mainly performed at the northern "altiplano" region using both manual and automatic milking systems. The product quality will define its commercialization directly to consumers after pasteurization or for processing and derivates production. In both cases, the initial microbial contamination is crucial for its final use. Colombian regulations, specific for regions, define the allowed values of colony forming units (CFU), so the producers not only can sell their production, but also obtain important price bonus. The objective of the present work was to study some factors that can affect the bulk milk CFU counts in northern Antioquia dairy farms. The dependent variable was measured, described with an unvaried analysis and associated with a logistic regression. $\mathrm{CFU}$, and independent variables as milking system, altitude, milking time in churn (minutes), distance to bulk (m) and cow number were measured, analyzed and associated with univariated and logistic regression statistics. Results indicated that the main risk factor in the CFU variation was 
the time period that the milk remained out of the cold chain. Other critical factors were the number of milked cows, since it increases the milking time; equally, altitude where farms are located, possibly related to temperature and bacterial proliferation.

Key words: Colony forming units (CFU), manual and automatic milking, Global Positioning System (GPS).

\section{INTRODUCCIÓN}

Si el destino primario de la producción de leche es el mercado líquido o el posterior procesamiento y la obtención de derivados, su vida de almacenamiento y la calidad en los procesos estarán reducidas, si se presentan altas concentraciones de células somáticas y/o de bacterias. La presencia de bacterias en leche vendría de tres principales fuentes: el medio ambiente, infecciones intramamarias y de la flora normal de la ubre (van Schaik et al. 2005).

La inocuidad de los alimentos se debe garantizar en cada uno de los eslabones de la cadena alimenticia y la producción primaria es el primer nivel. La calidad tanto de la leche cruda y pasteurizada como de los productos derivados lácteos es la consecuencia de todas las actividades desarrolladas durante el proceso de producción, desde las granjas hasta la transformación en la industria láctea (Vilar et al. 2011; WHO/ FAO 2008).

El nivel y el tipo de microorganismos presentes en tanque es información que refleja las condiciones higiénicas a varios niveles, durante la producción de leche en la finca. Existen varias metodologías para monitorear la calidad higiénica de la leche en tanque y son: conteo total de aeróbicosTAC (por Total Aerobic Count) o de unidades formadoras de colonias (UFC), que es una alternativa del conteo estándar en placa o SPC (por Stand Plate Count), conteo por incubación preliminar-PIC (por Preliminary Incubation Count), conteo por pasteurización de laboratorio-LPC (por Laboratory Pasteurization Count) y conteo de coliformes-CC (por Coliform Count), entre otros. El TAC o UFC, el más utilizado, estima el número total de bacterias mesofilicas aerobias totales presentes en leche cruda al momento de la toma de la muestra en tanque y provee una medida general de calidad higiénica de la leche; sin embargo, tiene un valor diagnóstico limitado, en lo que concierne a la identificación específica de la bacteria contaminante (Elmoslemanya et al. 2010).

Altos conteos de unidades formadoras de colonias (UFC) en leche, se asocian comúnmente con pobre sanidad o deficiencias en la cadena de frío que, a su vez, estarían asociados con varios factores, como ubres con mastitis, contaminación ambiental, contaminación por recipientes, tiempo y temperatura de almacenamiento y transporte (Gaviria, 2007). Es seguro que existen muchas otras variables que podrían tener efecto en estos conteos y que van a influir en los factores mencionados.

En Colombia, la resolución 0012 de 2007 reglamenta el pago de la leche cruda al productor primario sobre la base de parámetros de calidad composicional, sanitaria e higiénica, bonificando los conteos bajos de UFC en unidad de miles de UFC/mL y penalizando los recuentos altos (MADRCOLOMBIA 2007), medición realizada por la empresa acopiadora, para definir las bonificaciones.

La industria lechera colombiana, se desarrolla en explotaciones desde 0 hasta más de 3000 msnm y existe en diversas zonas del país. En Antioquia, la región del altiplano norte, se caracteriza por la alta producción de leche, en los municipios de Santa Rosa de Osos, San Pedro de los Milagros, Entrerríos, Belmira, Don Matías y San José de la Montaña; la producción primaria, se realiza mediante ordeño manual y mecánico en sala y en potrero.

Es importante anotar que el ordeño manual que se maniobra en estas zonas es una práctica que desapareció en muchos países hace mucho tiempo; sin embargo, en Colombia, tanto en el trópico bajo como en el trópico de altura, se realiza en un gran porcentaje de hatos (el $80 \%$ de los predios medidos, el $20 \%$ restante lo conforman los ordeños mecánicos en potrero y en sala).

En una publicación en cabras, al comparar tres tipos de ordeño (mecánico sala, en potrero y manual), reportaron los autores que el tipo de ordeño influye en los conteos de UFC en leche, siendo el ordeño manual el que está más relacionado con leche contaminada (Zeng \& Escobar 1996).

Aunque es indiscutible que la calidad de la leche cruda es esencial para la producción de leche y de productos lácteos de calidad. La información acerca de la influencia de factores de manejo sobre el conteo de bacterias en tanque y en diferentes tipos de ordeño es limitada, a nivel internacional y, más aún, a nivel local.

Este trabajo se realizó, con el fin de determinar cuáles serían las variables que más afectan el recuento de unidades formadoras de colonias en el tanque, en hatos que tienen ordeño manual, comparado con hatos que tienen ordeño mecánico, en fincas del norte antioqueño. 


\section{MATERIALES Y MÉTODOS}

Las muestras fueron tomadas en seis municipios del norte del departamento de Antioquia, en 13 fincas y en 290 potreros, durante 2009 y 2010 . Las mediciones, se realizaron en leche proveniente de tanque final con leche acumulada de 2 a 4 ordeños, con un promedio $2,8 \pm 0.8$ ordeños y una moda de dos ordeños. La variable dependiente que se estudió fue el recuento total de bacterias en tanque final y se expresa en unidades formadoras de colonias en miles por mililitro, UFC/mL, ya que es con esta unidad que la norma bonifica o castiga, como se mencionó anteriormente en la introducción. Este valor, se calculó como el promedio para los meses de 2009 y 2010 y se obtuvo mediante la técnica para microorganismos aerobios mesófilos totales y no específicos, utilizando el método de RIDA Count Total $^{\mathrm{TM}}$ en cultivos, por $24 \mathrm{~h}-36 \mathrm{~h}$, a $36^{\circ} \mathrm{C}$, en el laboratorio Syngamia, de la Universidad de Antioquia.

Se escogió el valor de 70.000 unidades formadoras de colonias para realizar los análisis por ser el valor que se presenta con más frecuencia, según resultados del análisis univariado (más adelante).

Las variables independientes fueron: tipo de ordeño, que se clasificó en manual, mecánico en potrero y mecánico en establo; altitud, medida en msnm y fueron datos obtenidos en una fecha, en todos los potreros donde rotaron las vacas de ordeño; se realizó por medio del equipo GARMIN®GPSmap 60CSx; tiempo que dura la leche en las cantinas, durante el ordeño y hasta llegar al tanque final y se calculó en minutos; se aplica para todos los tipos de ordeño a excepción de los que eran de tipo mecánico en establo con unidad final; se trata del tiempo que tarda la leche en ser depositada en el tanque final; distancia al tanque, en metros, es la distancia que recorre la leche o las cantinas con la leche para llegar al tanque final desde los potreros; se calculó en los ordeños manual y mecánico en potrero y, finalmente, número de vacas en ordeño, se incluyeron todos los animales que estaban siendo ordeñados en el momento de la toma de muestras para el cálculo de las UFC.

Análisis estadístico: a los datos se les realizó análisis univariados, para generar datos descriptivos de promedio, desviación estándar, error estándar y moda. Luego, se procedió a un análisis de regresión logística, que incluyó el estadístico de Wald, para verificación de significancias de coeficientes. En la tabla 1, se muestran las variables incluidas como posibles predictoras y su operacionalización. El tipo de ordeño y el número de vacas en ordeño, se incluyeron como variables categóricas y la primera categoría como de referencia; para las variables dicotómicas altitud y tiempo que dura la leche en cantinas, Alt_cat(1) y Tiemp_cant(1) fueron tomadas como de referencia.

Tabla 1. Variables incluidas como posibles predictoras de la contaminación microbiológica (UFC), en hatos lecheros del norte de Antioquia-Colombia.

\begin{tabular}{|l|l|}
\hline \multicolumn{1}{|c|}{ Variable } & \multicolumn{1}{c|}{ Operacionalización } \\
\hline Tipo de ordeño & $\begin{array}{l}\text { 1. Manual: Ord_tip(1) } \\
\text { 2. Mecánico Potrero: Ord_tip(2) } \\
\text { 3. Mecánico Establo: Ord_tip(3) }\end{array}$ \\
\hline Altitud (msnm) & $\begin{array}{l}1 .<2428 \mathrm{msnm:} \text { Alt_cat(1) } \\
2 .>2428 \mathrm{msnm:} \text { Alt_cat(2) }\end{array}$ \\
\hline $\begin{array}{l}\text { Tiempo que dura la leche en las cantinas durante } \\
\text { el ordeño (min) }\end{array}$ & $\begin{array}{l}1 .<90 \text { min: Tiemp_cant(1) } \\
\text { 2. } 90-120 \text { min: Tiemp_cant(2) }\end{array}$ \\
\hline $\begin{array}{l}\text { Distancia que recorre la leche para llegar al tanque } \\
\text { (m) }\end{array}$ & $\begin{array}{l}1 .<101.3 \text { Mts: Dist_tanq(1) } \\
2 .>101,3 \text { Mts: Dist_tanq(2) }\end{array}$ \\
\hline Número de vacas en ordeño & $\begin{array}{l}1 .<26 \text { vacas: Nun_vac_ord(1) } \\
2.26-50 \text { vacas: Nun_vac_ord(2) } \\
\text { 3. }>50 \text { vacas: Nun_vac_ord(3) }\end{array}$ \\
\hline
\end{tabular}




\section{RESULTADOS Y DISCUSIÓN}

Unidades formadoras de colonias-(UFC: Los niveles de UFC variaron entre 4500 (predio del municipio San Pedro) y 2103500 (en Entrerríos) con un promedio de 115932 UFC. El valor que se presentó con más frecuencia (moda) en los seis municipios muestreados es de 70000 UFC. Como se mencionó en la introducción, según la resolución 000012 de 12 de enero de 2007, la bonificación máxima a productores de leche de la región 2 (Antioquia, Quindío, Risaralda, Caldas y Chocó), se da en rangos de (UFC de 0 a 75.000 (MADR-COLOMBIA, 2007), lo que incluiría este valor de moda encontrado en el estudio.

La medición de contaminación microbiana, medida en UFC, mostró que los municipios de Belmira, San Pedro y Santa Rosa de Osos son los que tienen más predios, con menos de 70000 unidades formadoras de colonias.

Entrerríos aparece con un alto número de fincas, cuyo conteo mensual de UFC está por encima de los 70000. Finalmente, dos municipios: Don Matías y San José de la Montaña presentan un número similar de predios por encima y por debajo de la moda de 70000 UFC (Figura 1).

En esta investigación se utilizó un tipo de medición general de bacterias, como se explicó anteriormente, ya que no era objetivo del estudio definir el tipo de bacteria; sin embargo, se sugiere que para futuros estudios se empleen técnicas para la identificación de bacterias específicas para tratar de relacionarlas, según los puntos de riesgo (Elmoslemanya et al. 2010) y para proponer las soluciones más idóneas para su control o su erradicación.

UFC y tipo de ordeño: El ordeño es manual en el $80 \%$ de los predios medidos, el $20 \%$ restante lo conforman los ordeños mecánicos en potrero y en sala. En los predios con ordeño manual, se presentan valores de conteo bacteriano, que se distribuyen, tanto por encima como por debajo de la moda de 70000 UFC. El ordeño mecánico en potrero sólo presenta valores por debajo de 70000 UFC, así como el mecánico en establo, que arrojó en su mayoría conteos por debajo de la moda. En 1996, se reportó en cabras que el ordeño manual era más propenso a presentar altos recuentos UFC comparado con los tipos de ordeño mecánico en sala y en mecánico en potrero (Zeng \& Escobar 1996). En años anteriores, en un estudio en vacas, se concluyó acerca de la importancia de la preparación de la ubre antes del ordeño, ya que la higiene de ésta se podría ver afectada en el ordeño manual, por el número de vacas, el sellado, el secado, el tipo de papel para limpiar, tipo de desinfectante y recambio de este (Galton et al. 1986). Concluyeron los autores acerca del beneficio del secado manual de pezones, como paso del ordeño manual, mas que el tiempo o el tipo

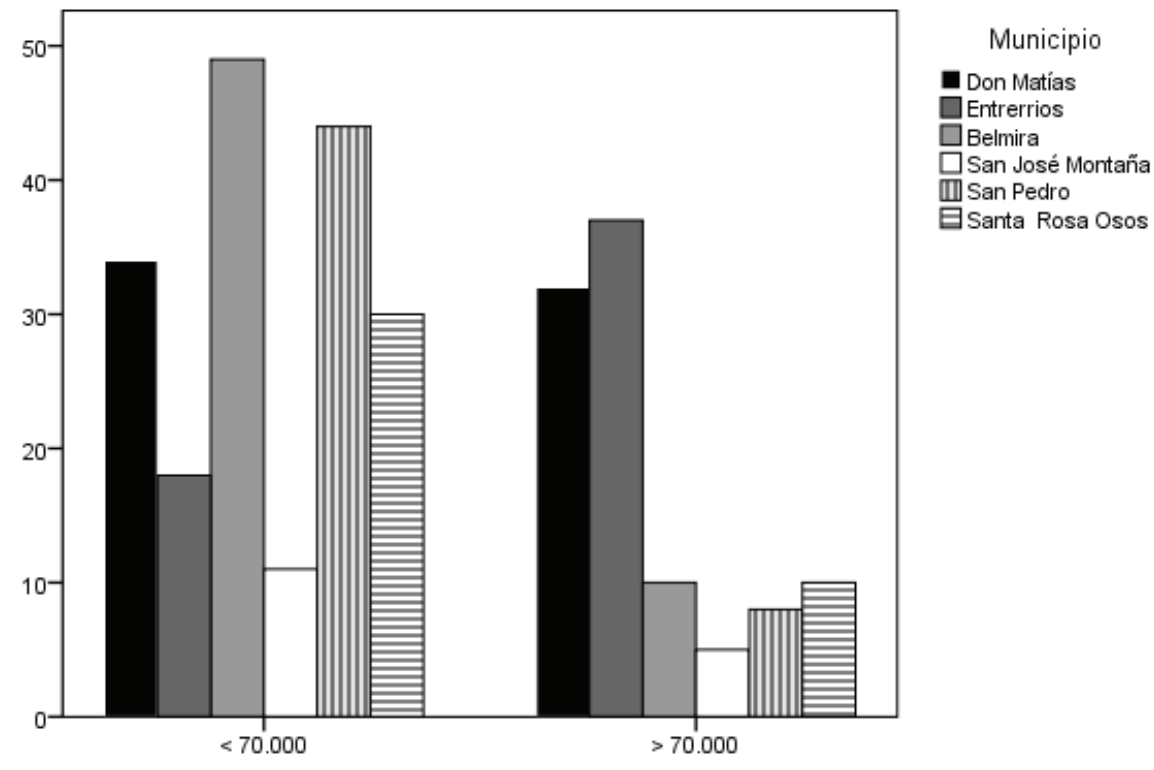

Unidades formadoras de colonias

Figura 1. Conteo de unidades formadoras de colonias (UFC), en seis municipios del norte de Antioquia, Colombia. Se tuvo en cuenta el valor más frecuente (moda de 70000 UFC), para estudiar conteos por encima y por debajo de este valor. 
de papel utilizado. Todas estas labores desempeñadas por operadores del ordeño manual, en la mayoría de casos con amplia experiencia en campo, infortunadamente no siempre se enmarcan dentro de las buenas prácticas en producción primaria de leche (Gaviria 2007). Sumado a esto, el número de vacas por operario y por sesión de ordeño, limita la aplicación de dichas prácticas, por falta de tiempo.

Se publicó recientemente (Gonzalo et al. 2010), que los factores que influyen en un 35,4\% del total de la variación de UFC en leche de ovejas en España, fueron el año, el mes, la terapia de secado y el tipo de ordeño. En el presente trabajo, no se encontró efecto del tipo de ordeño, quizás explicado por los porcentajes de tipos de ordeño mencionados que, en su gran mayoría, se hallan dentro del tipo manual.

UFC y altitud: La altitud presentó un promedio de 2428 msnm, con variaciones entre 2288 y $2700 \mathrm{msnm}$. Se trata, entonces, de trópico alto. Más predios medidos mostraron valores de UFC menores a 70000, cuando se hallaban a altitudes superiores de $2428 \mathrm{msnm}$; a altitudes menores, se muestra que los conteos de UFC, se encuentran tanto por encima como por debajo del valor de moda (Figura 2). El efecto de la altitud estaría relacionado, posiblemente, con la temperatura y la proliferación de bacterias. Altitudes mayores al promedio, analizados para este estudio (2428 msnm), corresponderían, en general, a temperaturas promedio bajas; este dato no fue analizado. A altitudes menores a 2428 msnm, el riesgo de presentarse UFC es más de cinco veces mayor $[\operatorname{EXP}(B)=5.432]$, que a altitudes mayores (Tabla 2).

UFC y tiempo de leche en cantina/tiempo al tanque: El tiempo que dura la leche en las cantinas antes de llegar al tanque de recolección fue en promedio de148,8 $\pm 31,4$ minutos, con un rango entre 90 y 180 minutos.

En la figura 3, se puede observar que la leche que se mantiene en tanques por menos de 90 minutos presenta conteos de UFC menores a los 70.000 UFC. Por otro lado, en el rango de 90 a 120 minutos de permanencia en las cantinas, las UFC varían por encima y por debajo de las 70.000 UFC. El tiempo transcurrido desde el ordeño hasta llegar al tanque sin alcanzar la cadena de frío es un punto crítico para el conteo de UFC, ya que aumentaría el riesgo de proliferación bacteriana.

Esto corresponde al tiempo que permanece la leche a la temperatura óptima para el crecimiento de mesófilos. Es importante tener esto en cuenta, dado que las distintas fuentes de contaminación de la leche al momento del ordeño y las condiciones de tiempo y de temperatura de almacenamiento, antes de llegar a la planta de recepción, definen el número de bacterias por mililitro, que en este momento se convierten en la población inicial para todos los procesos industriales, a que se destine esta materia prima (Gaviria, 2007).

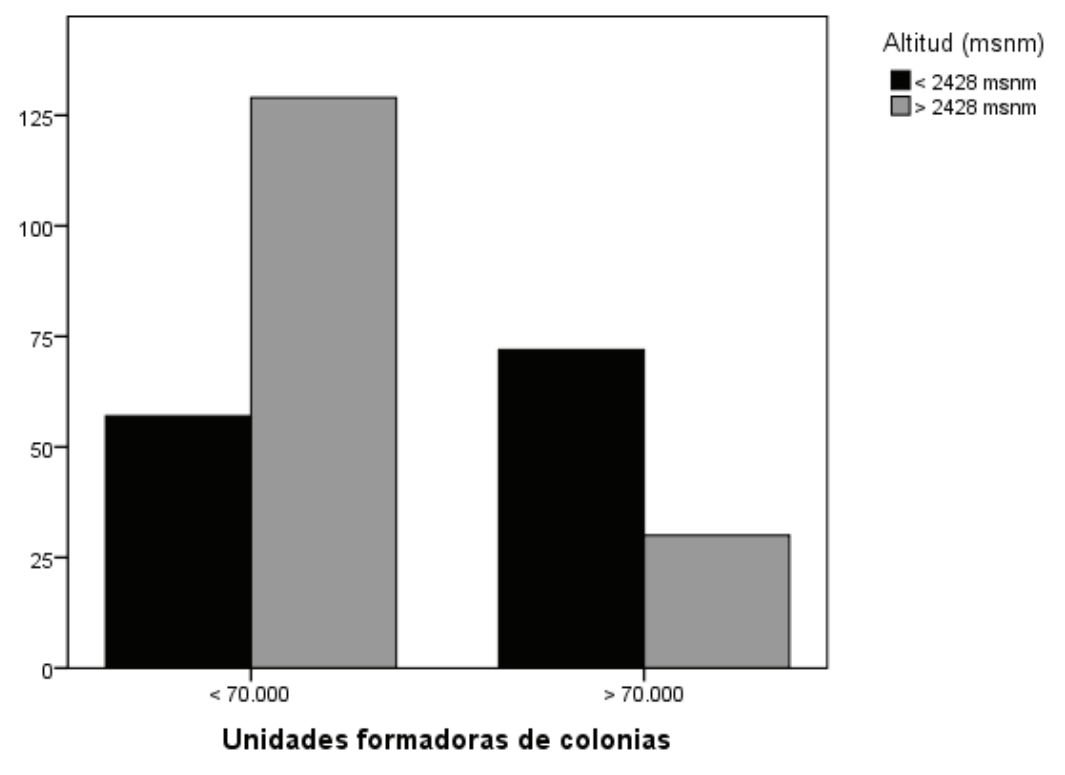

Figura 2. Conteo de unidades formadoras de colonias UFC, según la altitud promedio (msnm) en que se encontraban los predios, en seis municipios del norte de Antioquia, Colombia. Se tuvo en cuenta el valor más frecuente (moda de 70000 (UFC), para estudiar conteos por encima y por debajo de este valor. 
Tabla 2. Resultados de Regresión Logística. Para la variable dicotómica: altitud, se tomó como variable de referencia a Alt cat(1); ND: no hay dato; B, se refiere al coeficiente $\beta$ de la regresión; Sig: significancia (valor de p); Exp(B): exponencial de $B$, es el riesgo relativo de que ocurran las UFC, bajo la influencia de las variables que se muestran.

\begin{tabular}{|l|c|c|c|c|c|}
\hline \multicolumn{1}{|c|}{ Variables } & B & Sig. & Exp(B) & \multicolumn{2}{c|}{$\begin{array}{c}\text { Intervalo de confianza (95\%) } \\
\text { Límite Inferior }\end{array}$} \\
\hline Alt_cat(1) & 1.692 & ND & & & \\
Alt_cat(2) & & .000 & 5.432 & 3.204 & 9.2081 \\
\hline Nun_vac_ord(1) & .001 & & & 8.169 \\
\hline Nun_vac_ord(2) & 1.374 & .000 & 3.953 & 1.913 & 5.513 \\
\hline Nun_vac_ord(3) & .990 & .007 & 2.692 & 1.314 & \\
\hline Tiempo_cant(1) & & .003 & & & 6.610 \\
\hline Tiempo_cant(2) & .894 & .078 & 2.445 & .905 & \\
\hline
\end{tabular}

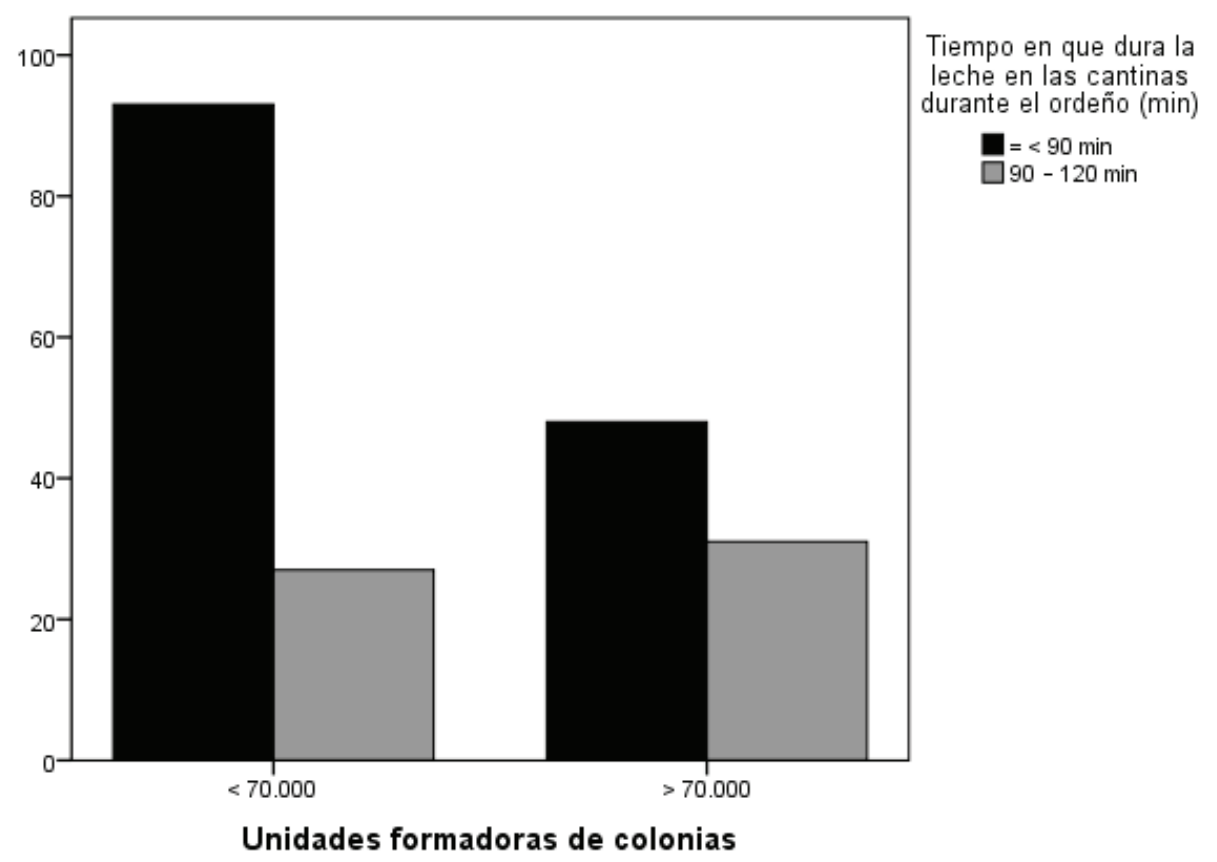

Figura 3. Conteo de unidades formadoras de colonias UFC, según el tiempo que dura la leche en las cantinas, durante el ordeño y antes de llegar al tanque de recolección, en predios de seis municipios del norte de Antioquia, Colombia. Se tuvo en cuenta el valor más frecuente (moda de 70000 UFC), para estudiar conteos por encima y por debajo de este valor.

En estudios acerca de los factores que influyen en los recuentos de bacterias de leche en tanque, se evidenció que muestras de leche que habían sido mantenidas a temperaturas bajas constantes (en laboratorio) presentaban conteos de bacterias totales más bajos, luego de incubación, comparado con leche que había sido refrigerada y había sufrido cambios. Publicaron, igualmente, que posibles factores responsables de altos conteos, luego de incubación preliminar, eran no sólo máquinas y baldes sucios sino, también, medidas sanitarias pobres, agua con altos conteos de bacterias totales y condiciones de tanque no satisfactorias (Morse et al. 1968a; 1968c).

Un estudio de caso reciente mostró que con una rutina de limpieza y de desinfección de la máquina de ordeño correcta, lo que merecía mejorar era la limpieza y la desinfección de 
los pezones, ya que contaminaban la pezonera que, a su vez, impurificaba los medidores y, finalmente, estas bacterias se acumulaban en tanque de frío (Ramón Estévez et al. 2011).

Sin embargo, en otra investigación, se concluyó que ni el pezón, ni el balde, ni la cantina, ni el tanque, como utensilios, son el punto crítico de control. Dicho punto sería el tiempo transcurrido desde el ordeño hasta el tanque sin alcanzar la cadena de frío, dada la alta correlación entre la variable tiempo y el conteo de UFC (Posada Arias et al. 2010), como sucedió en el presente estudio.

La regresión logística arrojó que al comparar la categoría 2 (entre 90 y 120 minutos) con aquella de referencia de menos de 90 minutos en cantina, se encontró que el riesgo de aumentar las UFC es más de dos veces mayor al permanecer la leche por más de 90 minutos en las cantinas. Es importante tener en cuenta que esta categoría no resultó significativa estadísticamente $(p=0.078)$, pero el intervalo de confianza indicaría una influencia importante de la variable (Tabla 2). Tiempo en cantina superior a 120 minutos, no mostró influencia en el riesgo de formación de UFC $(p=0,062$ e intervalo de confianza para $\operatorname{EXP}(B)$ de 0,130-1,050 (Tabla 2).

Una comunicación corta también se refirió al tema del almacenamiento de la leche de cabra en tanque en cuanto al uso de preservantes (azidio o bronopol), al uso de diferentes temperaturas $\left(4 \mathrm{y} 10^{\circ} \mathrm{C}\right) \mathrm{y}$ al efecto final en los conteos por citometría de flujo (Sierra et al. 2009), mostrando las ventajas de estos manejos, reflejado en la disminución de conteos. Parece importante sugerir este tipo de práctica asumiendo el factor de tiempo en cantina, como factor de riesgo para las UFC.

UFC y distancia al tanque: La distancia que recorre la leche hasta el tanque final varió en un rango de $5 \mathrm{~m}$ (en ordeño mecánico en establo) hasta 546m (en ordeño manual en potrero), con un promedio de $101,3 \mathrm{~m}$. La leche recolectada que debe recorrer distancias por debajo del promedio para llegar al tanque corresponde a muestras que presentan conteos en tanque de UFC inferiores a los 70000; sin embargo, hay una cantidad considerable de muestras en tanque que aun concerniendo a leche que recorre distancias superiores al promedio (más de $500 \mathrm{~m}$ ) presentan igualmente conteos inferiores a los 70000. La regresión logística no arrojó valores significativos, en cuanto al efecto de distancia al tanque y conteos de UFC.

Número de vacas en ordeño: El promedio de animales en

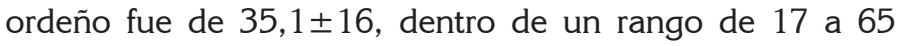
animales. Según la figura 4, a mayor número de animales en ordeño (grupo de 26 a 50 y grupo de mayor a 50 vacas), los conteos de UFC se encuentran en su mayoría por debajo de 70000. Para cantidades de animales inferiores a 26, las UFC estarían tanto por debajo como por encima del valor de 70000; no obstante, la regresión logística mostró un efecto significativo del factor "número de animales" sobre el aumento de UFC y podría estar explicado por el aumento en el tiempo que dura el ordeño. Estos dos grupos corresponden, en su mayoría, a ordeños tipo mecánico (potrero y sala), donde la calidad del manejo de los animales por el operario podría explicar este resultado, dado que se encontró que en promedio un sólo operario maneja los tres posibles grupos de animales, para este estudio, como se mencionó anteriormente, en cuanto al factor tiempo en cantina. Se podría especular también acerca de que un número mayor de animales, aumenta la probabilidad que alguno de ellos sea "foco" de contaminación, ya que las UFC se calculan en tanque final.

Desde 1968, se reportó en un estudio acerca de los factores que contribuyen al recuento de bacterias en tanque y más, específicamente, en lo relacionado con las UFC de muestras de vacas, como mediciones individuales. Los resultados fueron conteos de bacterias con promedios elevados y con amplia variabilidad. Explican esto los autores por la posible contaminación con bacterias del agua de suministro, pero, sobretodo, por un proceso de lavado y secado de ubres poco idóneo, lo que se traduce en un efecto individual de cada vaca a la contaminación en leche en tanque final (Morse et al. 1968b).

Sin embargo, más recientemente, se ha publicado que el número de organismos patógenos aislados en tanque final no guarda una relación directa con el número de vacas infectadas dentro de un rodeo, sino que se debe interpretar en conjunto con otras pruebas, como el conteo de células somáticas (RCS) (Calvinho, 2001). En el presente trabajo, no se encontró relación entre los RCS y las UFC (datos no mostrados).

El número de vacas entre 26 y 50 y de más de 50 animales en ordeño aumenta el riesgo de presentación de UFC en, aproximadamente, dos a cuatro veces $(\operatorname{EXP}(B)=2.69-3,95)$, al comparar con grupos de pocos animales (menos de 26 vacas), de manera estadísticamente significativa (Tabla 2). Este análisis es similar al encontrado en un estudio del 2010, donde se investigó la asociación entre los factores de manejo en la granja y la calidad de leche cruda, en cuanto a conteos totales de bacterias. Analizaron datos longitudinales para permitir estudio de efectos estacionales y para encontrar los factores de riesgo para TAC (UFC) y PIC, como referido en la introducción. La estación fue un predictor significativo para todo tipo de conteo de bacterias, con conteos más bajos en invierno; una inadecuada frecuencia de lavado ácido y el aumento del tamaño de la vacada fueron factores de riesgo (Elmoslemanya et al. 2010). 


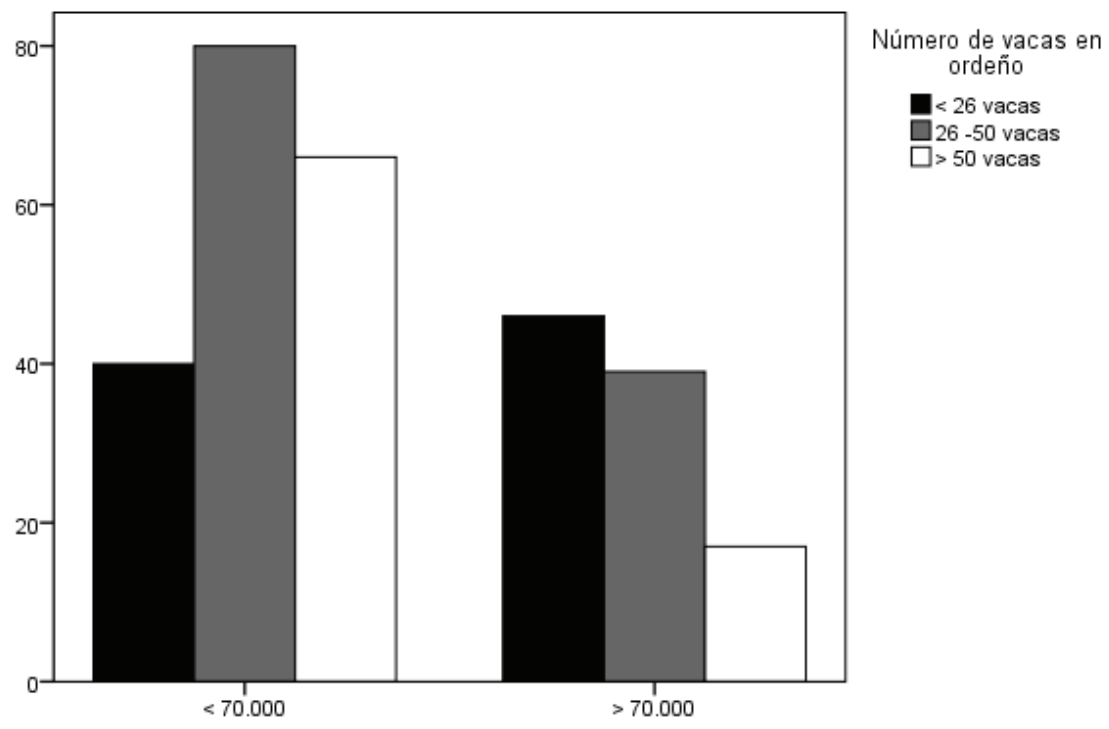

Unidades formadoras de colonias

Figura 4. Conteo de unidades formadoras de colonias UFC, según el número de animales en ordeño, en fincas de seis municipios del norte de Antioquia, Colombia. Se tuvo en cuenta el valor más frecuente (moda de 70000 UFC), para estudiar conteos por encima y por debajo de este valor.

Se recalca, la contribución importante del presente estudio, ya que no tuvo en cuenta períodos del año, como en ese estudio o en otros similares en ovejas (Gonzalo et al. 2010), por no existir estaciones en Colombia, pero sí incluyó variables diferentes, como la altitud, el número de animales y el tiempo en cantina, lo que enriquece el análisis para, finalmente, lograr buenas prácticas de ordeño y de control de carga microbiana. Las variables presentes en el modelo final de regresión logística fueron la altitud, el número de vacas en ordeño y el tiempo en la cantina.

Las pobres prácticas de higiene en el manejo de ubre, como fuente primaria de contaminación y el deficiente mantenimiento de la cadena de frío, se han catalogado como factores de obvia importancia, en la regulación del número de bacterias. El número de bacterias, se puede reducir disminuyendo, entre otras prácticas, el tiempo de transporte de leche, luego del ordeño manual o mecánico en potrero, hasta el tanque de enfriamiento.

En resumen, la presente investigación arroja que un punto crítico dentro de la rutina de ordeño, en cuanto a la contaminación microbiana, es el tiempo transcurrido desde el ordeño hasta el tanque, sin alcanzar la cadena de frío.

Otro factor crítico es el número de vacas, ya que esto estaría aumentando el tiempo que dura el ordeño. La altitud, por su posible relación con la temperatura y la proliferación de bacterias, también juega un rol influyente. Se necesitan análisis más puntuales, tanto en el tiempo (importante efecto de año y de mes) como en el lugar (buenas prácticas de manejo por predio), para poder concluir, de manera más segura, acerca de los factores más importantes que influyen en la contaminación microbiana por predio y poder realizar recomendaciones para lograr buenas prácticas de ganadería individual.

Agradecimientos: Financiación. Ministerio de Agricultura y Desarrollo Rural, proyecto cód.103-200802526-3153. Propietarios y administradores de las fincas incluidas en el experimento, en seis municipios del norte de Antioquia (Encanto 1, 2 y 3, Chupadero 1 y 2, Fortaleza, Primavera, San José, Molino, Fray Juana, Granja, Palmera, Reposo). Estrategia Sostenibilidad 2009-2010 al grupo Biogénesis, Universidad de Antioquia. Conflictos de intereses. El manuscrito fue preparado y revisado con la participación de todos los autores, quienes declaramos que no existe ningún conflicto de intereses que ponga en riesgo la validez de los resultados presentados.

\section{BIBLIOGRAFÍA}

1. CALVINHO, L. 2001. Diagnóstico bacteriológico de mastitis y su importancia en los programas de control. Disponible desde Internet en http://www. 
aprocal.com.ar/wp-content/uploads/diagnostico de_mastitis.htm.pdf (Brasil) (con acceso 2/09/2011).

2. ELMOSLEMANYA, A.; KEEFEA, G.; DOHOOA, I.; WICHTELA, J.; STRYHNA, H.; DINGWELLE, R. 2010. The association between bulk tank milk analysis for raw milk quality and on-farm management practices. Prev. Vet. Med. (Irlanda). 95:32-40.

3. GALTON, D.; PETERSSON, L.; MERRILL, W. 1986. Effects of premilking udder preparation practices on bacterial counts in milk and on teats. J. Dairy Sci. (USA). 69:260-266.

4. GAVIRIA, B. 2007. Calidad higiénica y sanitaria de la leche cruda. En: Buenas prácticas de producción de leche. Ed. Biogénesis, Universidad de Antioquia (Medellín-Colombia). 189p.

5. GONZALO, C.; CARRIEDO, J.A.; GARCIA-JIMENO, M.C.; PEREZ-BILBAO, M.; DE LA FUENTE, L.F. 2010. Factors influencing variation of bulk milk antibiotic residue occurrence, somatic cell count, and total bacterial count in dairy sheep flocks. J. Dairy Sci. 93:1587-1595.

6. MADR-COLOMBIA. 2007. Pago de leche cruda al productor. Ministerio de Agricultura y Desarrollo Rural. Resolución 000012, 2007.

7. MORSE. P.M.; JACKSON, H.; MCNAUGHTON, C.H.; LEGGATT, A.G.; LANDERKIN, G.B.; JOHNS, C.K. 1968a. Investigation of factors contributing to the bacterial count of bulk-tank milk. I. Influence of two-day storage and effect on results of preliminary incubation. J Dairy Sci. 51:1182-1187.

8. MORSE, P.M.; JACKSON, H.; MCNAUGHTON, C.H.; LEGGATT, A.G.; LANDERKIN, G.B.; JOHNS, C.K. 1968b. Investigation of factors contributing to the bacterial count of bulk tank milk. II. Bacteria in milk from individual cows. J Dairy Sci. 51:1188-1191.

9. MORSE, P.M.; JACKSON, H.; MCNAUGHTON, C.H.; LEGGATT, A.G.; LANDERKIN, G.B.; JOHNS, C.K. 1968c. Investigation of factors contributing to the bacterial count of bulk tank milk. 3. Increase in count, from cow to bulk tank, and effects of refrigerated storage and preliminary incubation. J. Dairy. Sci. 51:1192-1206.
10. POSADA ARIAS, S.; LOAIZA, E.; RESTREPO, J.; OLIVERA, M. 2010. Caracterización del ordeño manual e identificación de puntos críticos de control para la calidad higiénica de la leche en una finca del norte de Antioquia. Rev. Lasallista Invest. (Colombia). 7:35-46.

11. RAMÓN ESTÉVEZ, J.; RESTREPO BOTERO, J.; RUIZCORTÉS, Z.; OLIVERA ÁNGEL, M. 2011. Detección de riesgos de contaminación con microbios ambientales en un sistema de ordeño mecánico de un hato lechero del norte de Antioquia. Rev. Lasallista Invest. 8:7-15.

12. SIERRA, D.; SÁNCHEZ, A.; CONTRERAS, A.; LUENGO, C.; CORRALES, J.C.; DE LA FE, C.; GUIRAO, I.; MORALES, C.T.; GONZALO, C. 2009. Short communication: effect of storage and preservation on total bacterial counts determined by automated flow cytometry in bulk tank goat milk. J. Dairy Sci. 92:4841-4845.

13. VAN SCHAIK, G.; GREEN, L.E.; GUZMAN, D.; ESPARZA, H.; TADICH, N. 2005. Risk factors for bulk milk somatic cell counts and total bacterial counts in smallholder dairy farms in the 10th region of Chile. Prev. Vet. Med. (USA). 67:1-17.

14. VILAR, M.; RODRIGUEZ OTERO, J.; SANJUAN, M.; DIEGUEZ, F.; VARELA, M.; YUS, M. 2011. Implementation of HACCP to control the influence of milking equipment and cooling tank on the milk quality. Trends Food Sci. \& Techn. (UK). 20:1-9.

15. WHO/FAO. 2008. Codex Alimentarius. Animal food production. World Health Organization and Food and Agriculture Organization of the United Nations.

16. ZENG, S.; ESCOBAR, E. 1996. Effect of breed and milking method on somatic cell count, standard plate count and composition of goat milk. Small Rum. Res. (USA). 19:169-117.

Recibido: Septiembre 2 de 2011

Aceptado: Febrero 28 de 2012 